\title{
Relações de Gênero, Possessão e Sexualidade
}

\author{
PATRÍCIA BIRMAN *
}

\begin{abstract}
A imagem do candomblé na sociedade carrega muitos sentidos. Um deles, que de certa forma está na origem deste trabalho, diz respeito à relação que este sistema religioso mantém com o que seriam 'formas desviantes' de sexualidade. ${ }^{1}$ Não é de hoje que a relação entre cultos afro-brasileiros e comportamentos representados como desviantes se apresenta. Não foi outro, inclusive, 0 aspecto privilegiado pelos precursores dos estudos sobre religiões afrobrasileiras: charlatanismo, homossexualidade, prostituição foram temas destacados. Verdadeiros antros de perdição, face oculta dos homens de bem, envolviam a todos, homens e mulheres, pela tentação que os adivinhos ofereciam, ao lado da perversa manipulação de feitiçarias feitas nos trabalhos $e$ despachos das macumbas. Esta imagem, de mil formas presente nas crônicas de João do Rio, ${ }^{2}$ decerto não se encontra mais tão nítida na rígida linha divisoria que separa o mundo branco, civilizado, e o seu inverso pertencente aos negros, ex-escravos de vida escusa e marginal.
\end{abstract}

* Professora do Departamento de Ciências Sociais da Universidade do Estado do Rio de Janeiro.

1 Este texto apresenta, de forma condensada, os argumentos que desenvolvi no meu trabalho de tese (BIRMAN P., "Fazer estilo, criando gêneros". Tese de doutorado Rio de Janeiro, PPGAS/Museu Nacional, 1988).

2 JOÃO DO RIO, As religiões no Rio. Rio de Janeiro, Ed. Nova Aguilar, 1976. 
Contudo, outras nuances, outros motivos, permanecem vinculando o candomblé ao amplo universo do desvio na sua face sexual. Lugar de bichas, tem-se como certo. Suspẹitas sobre a masculinidade de seus pais-de-santo são esperadas. Esta marca (por vezes) infeliz faz parte da imagem dos homens que se vinculam aos terreiros. Alguns se antecipam. Afirmam de maneiras variadas a condição de membros efetivos desse peculiar contingente; são pais e filhosde-santo bichas, personagens que habitam o universo urbano nos seus espaços mais decididamente públicos, seus meios de comunicação - apresentam-se em jornais, revistas e programas de televisão e fazem parte do reservatório de tipos sempre explorados nos programas de humor. A associação entre campo religioso afro e sexualidade constitui, pois, referência de uso corrente e objeto permanente de discussões nas conversas sobre as casas de santo. Nestas conversas busca-se formular uma resposta satisfatória para esse fenômeno: "por que tem tanta bicha nas casas de candomblé?"

Há nessa pergunta uma tematização implícita a respeito da relação que a sociedade mantém com esse seu segmento religioso: lugar apropriado para 0 gênero que se designa como bicha. Neste mesmo movimento encontra-se outro campo de significações: aquele que permite traduzir o significado atribuído a certos personagens que emergem do interior dos terreiros por outros significados associados às relações de gênero existentes no universo social mais amplo. Há uma constante busca de analogias entre o gênero social da bicha e os indivíduos de sexo masculino no candomblé. Não se trata de clamar contra a injustiça dessa identificação, mas sim de tentar compreender os movimentos que, de certo modo, permitem que ela aconteça. Movimentos que colocam em relação dois sistemas de representação sobre os sexos, um religioso e outro leigo.

Com efeito, a questão que para mim adquiriu importância diz respeito aos papéis religiosos que permitem esse jogo de analogias. Trata-se de indagar principalmente sobre a existência, no candomblé, de uma elaboração religiosa dos gêneros, que de certo modo torna fácil relacionar alguns papéis de gênero a outros, provenientes de um domínio social distinto. Seria talvez mais fácil supor que, neste caso, o movimento impulsionador da relação entre religião e sociedade reside somente em um de seus pólos. As freqüentes acusações aos cultos afro-brasileiros que privilegiam essa face relacionada ao sexo e ao desvio não precisam, para se efetivar, de nada além do que buscar analogias superficiais entre personagens tão negativos da sociedade e esse domínio social já tão claramente demarcado como lugar de múltiplas faltas. Escolhi outro caminho, tentando compreender a elaboração que o sistema religioso faz dos gêneros e a relação que assim mantém com a sociedade. 


\section{Identidades religiosas e seus critérios}

A classificação dos grupos afro-brasileiros em alguns contextos (notadamente no Rio de Janeiro, pela forma como neste estado se desenvolveu a 'herança africana') privilegia uma divisão primária entre duas grandes classes: aquela designada usualmente como umbanda e a outra, que engloba algumas variações, designada como candomblé ou cultos de nação. Entre estas duas grandes vertentes, referidas através de atributos diversos, somente sobre uma recai a tematização da sexualidade.

As referências à sexualidade associadas aos cultos afro se fazem usualmente direcionadas a um de seus segmentos, designado como candomblé. As casas de candomblé estão de maneira geral sujeitas a comentários em relação à presença de sexualidades 'desviantes'. Assim, os grupos de cultos recebem avaliações diferenciadas, aliás constitutivas de suas proprias identidades.

Ora, a elaboração dessas identidades religiosas não se faz mediante critérios universais: cada vertente religiosa justifica a seu modo o que a distingue e a separa das outras. Para compreender as razões pelas quais se articulam de maneira específica sexualidade e candomblé, buscamos alcançar um determinado ponto de vista, aquele de uma perspectiva religiosa específica. Em suma, tentamos entender como esta elabora suas diferenças em relação aos outros e que sentido a sexualidade possui na estruturação desse campo de diferenças.

A minha pesquisa de campo foi realizada no Rio de Janeiro, na Baixada Fluminense, onde se concentra um número expressivo de terreiros: muitos se consideram pertencentes, com algumas variações, à linha de nação, ou ainda a mais de uma linha, como angola e umbanda ou keto e umbanda, candomblé de caboclo. Mesmo quando um terreiro, através de seu pai-de-santo, destaca uma filiação exclusiva ao candomblé, ressalta a presença de rituais voltados para entidades de umbanda como uma exigência própria e inescapável da vida religiosa.

As referências à questão das identidades religiosas 'mistas', ou a mais de uma filiação religiosa, são importantes para entender essa perspectiva. Exigem, para serem compreendidas, que se dimensione devidamente o significado atribuído por esses grupos ao 'campo religioso' e às suas divisões internas, designadas como linhas. Com efeito, tem-se a idéia de que vertentes religiosas distintas 'misturam-se' no interior de um mesmo grupo de culto, como 'misturam-se' também no interior de cada pessoa. A unidade elementar desta 'mistura', designada como linha, tem um significado religioso bastante preciso: refere-se a uma divisão cósmica que pertence simultaneamente aos planos 
natural e sobrenatural. Através de várias destas linhas, que nos deixam entrever as várias faces dos vários deuses e entes do universo, a multiplicidade do cosmo se apresenta também na Terra. Não se trata, pois, de diferenças entre homens em razão de suas fraquezas terrenas, ${ }^{3}$ mas de diferenças inscritas na própria natureza do cosmo, cuja constituição abriga não um único deus, mas vários.

Temos, pois, que certas linhas - somente algumas, aquelas concebidas como parte do conjunto designado candomblé, que agrupa as linhas de nação - que apresentam o fenômeno que pretendemos analisar, ou seja, a articulação com a sexualidade no plano social mais amplo, a presença de um sistema de distinção de gêneros em que se destaca uma relação de analogia com aqueles considerados 'homossexuais' e/ou 'bichas' na sociedade., 5

3 Muito menos está em jogo a idéia de um campo onde se encontram 'opções' de crença entre sujeitos livre-contrastantes que, em nome de suas consciências, as realizam. A idéia de 'crença', como a tradição cristã nos acostumou a compreender, dificulta a percepção 'nativa' das distinções e segmentações do campo religioso. Para problematizar esta noção ver, POUILLON J., "Remarques sur le verbe croire", in IZAR M. e SMITH P. (orgs.), La function symbolique, Paris, Gallimard, 1979; NEEDHAM R., Beliet, language and experience. Oxford, Basil Blackwell, 1972; DUARTE L.F., "Pluralidade religiosa nas sociedades complexas e 'religiosidade' das classes trabalhadoras urbanas", in Boletim do Museu Nacional. Antropologia, 41, 1983; e BIRMAN P., Modos periféricos de crenças. Rio de Janeiro, ISER, 1991.

4 No seu estudo precursor sobre sexualidade na sociedade brasileira, Peter Fry contrapôs dois grandes modelos. Um deles, o chamado modelo hierárquico, distingue no caso do sexo masculino dois gêneros inconfundíveis, o do 'homem' e o da 'bicha', através do papel sexual atribuído a cada um deles. Modelo amplamente dominante nas camadas populares, sofre pouca concorrência com outro, de matriz igualitária, no qual não cabe distinguir os gêneros através do papel sexual na relação entre dois homens: ambos seriam igualmente 'homossexuais'. É o primeiro modelo que alimenta a discussão no candomblé. [Cf. FRY P., Para inglês ver. Rio, Zahar, 1982.]

5 Apesar de pouco mencionado, um fenômeno interessante diz respeito ao lugar concedido ao candomblé pela sociedade num sentido bem específico: este alimenta com termos provenientes da linguagem do santo, africana e nagô as metáforas de caráter sexual em uso freqüente por certos grupos sociais - não são poucos os termos que designam, adjetivam, destacam personagens e modos de ação diversos que emergem nos espaços periféricos da sociedade. Talvez fosse útil imaginar que a presença da linguagem religiosa africana é mais extensa do que o nosso conhecimento permite entrever, servindo como um dos meios para efetivar comentários jocosos sobre e entre as pessoas que freqüentam os circuitos periféricos dos travestis, michês, prostitutas etc, onde a tematização de papéis sexuais se faz intensamente presente (cf. PERLONGHER N., $O$ negócio do michê. A prostituição viril. São Paulo, Brasiliense, 1987). Essa suposição nos envia ao movimento inverso àquela inicialmente aventada: o sistema religioso fornecendo sentido para relações que se encontram fora dele e que podem ser tematizadas por seu intermédio. É possível, pois, indagar sobre o lugar que o candomblé fornece à sexualidade, diante de tantas associações que se fazem nesse sentido. 
O gênero no candomblé se apresenta através de dois eixos inter-relacionados; as formulações básicas de sua concepção do universo, particularmente sua concepção de pessoa, e a hierarquia religiosa, expressa na divisão de papéis da família-de-santo.

Comecemos pelo primeiro. É preciso remontar às qualidades diferenciais consideradas pertinentes para os segmentos religiosos afros. Evidentemente, apreender o significado das divisões do campo religioso é fundamental para que se entenda a afirmação que fizemos, de que apenas uma vertente dos cultos afros possui, reconhecidamente, o poder de atrair bichas e de transformar as relações religiosas em algo também associado às relações entre os sexos.

Essas divisões são qualificadas em função de uma modalidade de trajetória religiosa que é comum entre os freqüentadores das casas-de-santo que observamos. A experiência da maioria dos freqüentadores dessas casas apresenta uma constante: eles iniciam a vida religiosa em terreiros de umbanda participando de suas giras de preto-velho, caboclo, exu - e depois se deslocam para terreiros de candomblé, onde são submetidos ao processo de iniciação. $O$ momento inaugural das carreiras religiosas é aquele em que passam a dominar a concepção de sobrenatural que preside as giras de umbanda. As linhas de umbanda adquirem outro eixo de significação a partir da entrada para terreiros de candomblé, onde emerge toda uma outra ordem de questões, exigindo uma reordenação desse campo de significados. Os poderes e atributos de cada uma dessas vertentes religiosas são assim elaborados a partir de critérios fornecidos pela interpretação candomblecista, dominante entre os terreiros que pude observar. O que se apresenta como fundamental nesta interpretação?

No candomblé, o mito instaurador de todos os procedimentos rituais e simbólicos é aquele que diz respeito à existência de dois mundos, um terreno e outro divino, que no início dos tempos constituíam um todo único. Por efeito de certas ações desastrosas dos orixás, terminaram se separando definitivamente em dois: $o$ aiê e o orum, a Terra e o Céu. O orum, mundo originário, fonte divina de todas as coisas, está para sempre separado do mundo em que vivemos - este, como mundo criado e cultivado, representa a face humana, conhecida e terrena, na qual podemos existir.

A entrada para o candomblé pode significar, para os seus adeptos, uma mudança significativa no que diz respeito ao contato com o sobrenatural e aos atributos pessoais advindos deste contato. Se considerarmos a noção de pessoa presente neste pensamento religioso veremos que a possessão 
desempenha um papel fundamental. Não se trata, como bem discutiu Márcio Goldman, ${ }^{6}$ de considerar que orixás e espíritos seriam atributos homólogos aos que se encontram presentes na personalidade de cada um - neste caso, argumenta o autor, teríamos o candomblé como um mero sistema classificatório capaz de operar distinções entre pessoas, como faria um sistema totêmico 'clássico', conforme Lévi-Strauss analisou. No sistema religioso do candomblé, ao contrário, constrói-se uma noção de pessoa que, em vez de 'corresponder' a traços advindos da esfera sagrada, emerge como uma resultante do contato entre as duas esferas. Este contato, que ocorre por intermédio da possessão, tem efeito transformador.

Márcio Goldman apresenta uma hipótese interessante em relação à possessão. Faz uma crítica aguda da bibliografia, buscando superar o que considera como o seu grande dilema: ora a possessão se apresenta como expressão de relações dadas exclusivamente no plano de uma morfologia social, ora concerne ao plano psicológico, tendo como função promover uma adequação às normas sociais ou uma integração psíquica da personalidade, ou ainda exprimir conflitos intrapsíquicos. A superação desse dilema exige percebê-la como um rito, que no seu efeito simbólico atua como elemento fundamental na elaboração de uma noção de pessoa, essencial nesse sistema religioso. O rito de possessão não 'repete' o que o mito estabeleceu, mas, através do mecanismo simbólico que lhe é proprio, atua metonimicamente, juntando, no iniciado do candomble, aquilo que miticamente foi separado na origem do mundo e que deve ser recuperado na pessoa. O efeito da possessão é pois social, sem que seja somente sociológico e pessoal e sem que se reduza à idéia de um indivíduo já dado, segundo numa matriz psicologizante de pensamento. ${ }^{7}$

Esse contato, realizado pela possessão, vai se fazer relacionando domínios distintos; no aiê, o indivíduo 'recebe' na sua cabeça algo advindo do orum. O processo de iniciação introduz o noviço em algo que passa efetivamente a representar um outro mundo, e este contato com uma esfera sobrenatural não elimina aquela que ele conhecia. A partir da iniciação, os espíritos reconhecidos como pertencentes à linha de umbanda serão vistos como lógica e funcionalmente subordinados à esfera fundamental, fonte primeira de todas as substâncias, os orixás, matéria eterna da natureza, presente em todos os seres e, a partir da iniciação, 'fixada' em sua pessoa.

6 GOLDMAN M., "A construção ritual da pessoa", in MOURA C.E.M. (org.), Candomblé. Desvendando identidades. São Paulo, EMW Editores, 1987.

7 Idem. 
O reordenamento do valor que as linhas passam a ter não se faz através de palavras, de proselitismo por parte dos pais e mães-de-santo. Como vários autores já frisaram, acontece paulatinamente, por meio de um aprendizado de ensaio e erro, que é a forma de aprendizado pertinente a esse universo iniciático. Uma das questões fundamentais nesse processo, no meu modo de entender, diz respeito a prática dos ritos de possessão. Todos aqueles que só conheciam a possessão por intermédio da linha de umbanda precisam aprender a distinguir a presença de uma outra modalidade, que não se reduz à primeira e que, ao contrário, possui, além do mais, um valor inigualável. A posse desse valor, ou o reconhecimento pleno dessa diferença, é essencial para compor a identidade de um integrante de uma casa-de-santo de nação.

A diferença que distingue os cultos denação e aqueles associados somente ao domínio da umbanda se duplica na diferença que separa as ações e os entes relacionados ao domínio que, no candomble, se designa como orum, em oposição ao domínio designado como aiê. Domínio da Terra versus o domínio do Céu, representações básicas do cosmo no seu corpo doutrinário. Estamos dizendo, portanto, que a distinção entre as linhas de nação e as de umbanda duplica a distinção mítica, e de fundamental importância para essa cosmovisão, entre o aiê e o orum. A umbanda é pensada como uma linha que tem poderes somente associados aos entes e espíritos em contigüidade com o aiê, enquanto o candomblé é capaz de dar conta dos entes pertencentes ao orum.

$\mathrm{O}$ acompanhamento de alguns casos desse aprendizado me possibilitou compreender o quanto ele é ao mesmo tempo difícil e extremamente simples para os filhos-de-santo. Com efeito, oriundos da prática ritual da possessão umbandista, todos dominam uma elaboração ritual que ganha sentido na medida em que estabelece, no plano simb6lico, mecanismos capazes de apresentar as entidades sobrenaturais como verossímeis, porque assemelhadas a seres terrenos. As entidades de umbanda são construídas como seres em contigüidade com o mundo humano - seres que já viveram, portanto. Com efeito, a elaboração ritual da possessão umbandista deixa entrever que o sobrenatural é percebido como uma instância que traz duplicadas as relações que conhecemos no mundo terreno. A possessão considerada umbandista se realiza de forma a construir ritualmente os personagens que 'descem' nos terreiros, de modo que estes se tornam verossímeis por apresentarem traços semelhantes aos das pessoas vivas. Para provar que são 'verdadeiros', precisam pois se mostrar o mais próximo possível da experiência vivida no cotidiano dos homens. Esta forma de possessão traz implícita a representação da esfera sobrenatural. $\mathrm{O}$ mundo das entidades e espíritos é composto por seres que são imagem e 
semelhança dos vivos. Como estes - dos quais estão separados pela morte estão sujeitos a transformações, submetidos, portanto, ao tempo e seus influxos.

Esse rito umbandista apresenta duas relações de continuidade tematizadas; aquela que permite o contato com esse mundo sobrenatural e a apresentação desse mundo como uma continuação do outro. A partir da iniciação candomblecista, o que temosé o rompimento com uma representação do mundo sobrenatural, de forma a tê-lo essencialmente distinto do mundo terreno. A possessão se faz, assim, entre dois campos cuja natureza é essencialmente diversa. Passa a ser fonte de ridículo, e sinal de uma iniciação não operante e falsa, praticar a possessão na linha de nação como se fosse da linha de umbanda, vale dizer, apresentar orixás na Terra como se estes fossem humanos, com modos de agir calcados numa semelhança com a ordem terrena.

A 'prova' do contato com essa esfera, de natureza diversa, se efetiva quando os filhos-de-santo em transe são capazes de se comportar da mesma forma como se comportaria um ente subordinado à esfera divina. Quando viram, os orixás comportam-se como verdadeiramente um orixá deve se comportar, e não como se fossem espíritos de um caboclo, de um preto velho. $\mathrm{O}$ gestual dos orixás em Terra, um verdadeiro bale, apresenta-se na imutabilidade que somente divindades possuem. Assim, pode-se observar que efetivamente pertencem a um universo em total descontinuidade com o mundo humano $\mathrm{e}$ terreno.

A entrada para o candomblé passa a significar o acesso a um mundo sobrenatural que, na sua alteridade fundamental, a possessão umbandista não consegue alcançar: esta, em decorrência dessa nova experiência, serápercebida como uma linha integrante do aiê, exatamente por apresentar ritualmente uma relação de continuidade entre a experiência de vida de cada um e o que ocorre nessa esfera sobrenatural. A possessão umbandista contenta-se em efetivar os elos necessários com uma esfera próxima da esfera humana, aquela a que pertencem os espíritos dos mortos, as entidades, as almas.

A qualidade propria do orum, como domínio, é apreendida na medida em que fique demonstrado que, no rito, o filho-de-santo está sendo possuído por algo cuja natureza não se confunde com os elementos de origem humana. Essa demonstração, que exige perícia ritual e competência religiosa, é fundamental na passagem da umbanda para o candomblé. Não se pode, então, banalizar a experiência religiosa que possibilita a passagem do contato com essa esfera (que apresenta os seres do outro mundo como seres que possuem a mesma substância dos homens) para o contato com uma esfera que so se instaura quando ritualmente se torna possível apresentá-la como distinta e separada da primeira. 
Na sua exigência de mestria, o ritual de possessão impõe um campo de diferenças, ao apresentar a todos um outro mundo, incorporado no(a) filho(a)de-santo, como parte constitutiva de sua pessoa, agora de posse de uma dimensão que não está inscrita no corpo das demais. É por seu intermédio que se alcança algo cujo sentido é associado à exterioridade do mundo humano, não contaminado por seus limites, impensável caso todos se vissem circunscritos unicamente por suas fronteiras. O caráter não humano dessa inscrição - ao mesmo tempo apresentada e possibilitada pela possessão, rito que busca 'juntar' o aiê com o orum - nos permite compreender o quanto estamos distantes de uma noção de pessoa cuja dimensão fundamental é a de um 'eu' interior e psicologico: esses 'traços' não equivalem a dimensões psicológicas do humano - ao contrário, só passam a existir na medida em que se qualificam por oposição a essa esfera terrena. Se os ritos não fazem nada além de reiterar uma 'personalidade' previamente existente, ou no máximo contribuir para melhor 'integrá-la', é impossível compreender o sentido que essa relação ritual possui na sua potência criadora. ${ }^{8}$

Essa mesma dificuldade gerada pela não-relativização da noção de pessoa se apresenta através da percepção dos efeitos que a prática da possessão engendra em relação aos gêneros. Um argumento recorrente na bibliografia enfatiza a relação entre candomble e 'homossexualidade' como 'efeito' de uma identificação entre dois elementos análogos. Assim, orixás bissexuais 'pertencem' a indivíduos cuja natureza é 'homossexual'. A feminilidade nos homens, filhos-de-santo, revelaria algo que estaria inscrito nas suas personalidades, como os traços provenientes de seus orixás permitiriam entrever. Ora, este argumento nos obriga a supor que o contato com a esfera sobrenatural não teria, por si so, um efeito constitutivo para a idéia de pessoa no candomblé. O contato ritual da possessão oferece um outro efeito - incide também sobre a definição de gênero, particularmente no caso de indivíduos do sexo masculino.

Estamos supondo, pois, que a possessão se instaura como um peculiar operador da distinção entre os gêneros: os indivíduos do sexo masculino que entram em possessão se afastam de uma masculinidade plena. No imaginário desses cultos várias representações vinculam a feitura do santo (por parte de homens) à perda da masculinidade. Com efeito, várias relações na vida religiosa apontam para uma qualificação diferencial em termos de gênero, a partir das

8 Os traços psicológicos e a correspondência que possuem com os elementos constitutivos dos orixás são minuciosamente descritos por Lépine (LÉPINE C., Bandeiras de Alaira, organizado por Carlos Eugênio Marcondes de Moura, 1982). 
distinções que apresentam as duas esferas, aiê e orum, para adeptos do candomblé. Se há dúvidas entre os adeptos e estudiosos do candomblé a respeito da pertinência dos homens ao domínio dos orixás, tal coisa não se coloca a respeito do mundo dos espíritos. Exemplifiquemos com alguns argumentos.

Nos candomblés tradicionais, pratica-se em algumas casas o culto dos eguns - culto dos mortos -, interditado às mulheres: elas não fazem parte dessa confraria masculina e nem podem se aproximar de seus segredos. $9 \mathrm{Da}$ mesma forma como o domínio dos mortos deve, em todos os terreiros, ser mantido separado do domínio dos orixás, as divindades não se aproximam dos fiéis quando estes estão próximos da morte. É o caso de Xangô, sempre mencionado, que se afasta, horrorizado, ante qualquer indício de morte. Sobre o caráter oposto e antagônico dos dois domínios, diz sugestivamente Juana Elbein dos Santos: "Enquanto os Irúnmale-entidade divinas, os orisá estão associados à origem da criação e sua própria formação, e seu àse foram emanações diretas de Olórun, os Irúnmale-ancestrais, os egun, estão associados à história dos seres humanos. Pertencem a categorias diferentes: os orisá estão especialmente associados à estrutura da natureza, do cosmo; os ancestrais, à estrutura da sociedade (...) Os orisá regulam as relações do sistema como totalidade; os eguns, as relações com a ética, a disciplina moral de um grupo ou segmento." (Elbein dos Santos, 1977: 102, 104.)

Temos, pois, a relação dos homens com o mundo terreno, que se apresenta também como o mundo dos ancestrais, espíritos dos mortos, mundo que instaura o campo da ética e da disciplina moral. Este mundo é masculino e cultivado, em oposição àquele, representado como feminino e da natureza, o domínio dos orixás. Para os indivíduos do sexo masculino se manterem plenamente concernidos à esfera que lhes é própria, enquanto homens, é preciso então que não virem no santo. A possessão nesse caso, oposta à esfera da ancestralidade, atribui a quem a pratica qualidades pertencentes a esse domínio distante e separado do mundo dos eguns, o orum, onde residem as forças da natureza na forma dos orixás. O contato com essa esfera divina parece uma 'saída' do mundo: como se o indivíduo por certos instantes estivesse além das determinações que no cotidiano o subordinam. E o cotidiano, o mundo terreno, inegavelmente é masculino.

Há uma clara homologia entre esses campos de diferenças: $o$ reino dos orixás se opõe ao reino dos eguns da mesma forma que o gênero masculino ao feminino e a linha de umbanda ao candomblé.

9 Cf. ZIEGLER J., Os vivos e a morte, Rio de Janeiro, Zahar, 1977; ORTIZ R., "A morte e sua sombra," in MARTINS J.S. (org.), A morte e os mortos. São Paulo, Hucitec, 1983. 
A contigüidade com o mundo dos espíritos, cultivada pela umbanda, e a ausência de contato com a esfera separada dos orixás afastam dessa linha o perigo que está sempre rondando as casas de candomblé: a presença de homens considerados 'bichas' ou 'homossexuais'. Na umbanda, dizem todos, não há bichas. As explicações para essa ausência remetem, via de regra, ao caráter pouco atrativo da gira de umbanda, vale dizer, o momento ritual da prática da possessão, quando os filhos-de-santo 'trabalham' com as suas 'entidades', que entre as suas virtualidades, não apresentam grandes poderes de sedução. Os adés (personagens religiosos considerados 'bichas do candomblé') não gostam, porque - segundo comentam - não podem exibir muitas danças de seus orixás.

\section{Família-de-santo e papéis de gênero}

Quando se fala de gênero com o intuito de enfatizar a diferença que este termo introduz em relação a sexo, busca-se destacar o caráter social dessa distinção, afastando a recorrente idéia de que seu sentido esteja submetido a uma determinação biológica. Com efeito, a presença de homens e mulheres no candomblé, envolvendo acusações de 'homossexualidade', coloca imediatamente em questão aquilo do que se fala quando se faz uma referência ao gênero; é o gênero que o pesquisador atribui de acordo com seus critérios classificatórios? É o que a sociedade inclusiva elabora em termos da sua própria definição de gênero? Éo código dominante na sociedade? Não poderá ser algum outro, minoritário ${ }^{10}$ Ora, no caso do candomblé, encontramos freqüentemente acusações em que este é apresentado como um lugar de bichas. Antes de analisar o campo específico relacionado a essas acusações, é preciso voltar à esfera das relações entre as pessoas, concebida como relações de família família-de-santo, bem entendido.

Há na bibliografia uma longa discussão a respeito dos estatutos de gênero existentes nas religiões afro-brasileiras. Ela versa também, em conseqüência, sobre as proibições rituais que envolvem homens e mulheres. Frente ao domínio sobrenatural importam as diferenças de gênero? Podem homens e mulheres executar os mesmos ritos e deter as mesmas atribuições em relação às divindades? Nessa discussão, cujo pano de fundo era a questão do relacionamento dos grupos de culto com a homossexualidade, debatia-se apaixonadamente se, primeiro, o candomblé permitia homens nas casas-de-santo e, segundo, se os

10 FRY P., Para inglês ver, op. cit. 
homens que lá se encontravam eram ou não 'homossexuais'. E, ainda, se a homossexualidade era decorrência direta ou indireta das exigências diferenciadas que o candomblé estabelece para homens e mulheres. Em 1947, Ruth Landes $^{11}$ deu início a essa controvérsia que se estende até hoje. Sua hipótese fundamental é de que o candomblé abriga 'homossexuais' porque historicamente se constituiu como um matriarcado. Todos os papéis religiosos pertenceriam às mulheres. Os homens que os ocupassem, apesar de homens no plano biológico, seriam identificados como mulheres no plano social.

Nesse debate, é interessante ressaltar o quanto se mostrava incômoda a diferença que o candomblé apresentava no tratamento concedido ao sexo biológico, tão pouco naturalista este se apresentava. Isso era uma dificuldade a mais para os pesquisadores, já que se mostrava complicado compatibilizar essas diferentes perspectivas. $\mathrm{O}$ direcionamento que predominou na bibliografia é o que explora uma identificação positiva e normativa entre possessão e mulheres. A estranheza produzida por esse sistema transformou um lugar feminino em algo a ser obrigatoriamente preenchido por mulheres. Não somente isso não acontecia, como fazia emergir com toda a sua estranheza a ambigidade sexual constitutiva dos filhos-de-santo.

A possessão não só pertencia exclusivamente às mulheres, como afetava o gênero dos homens que nela se aventurassem. E mais: os homens que não praticavam a possessão não pertenciam ao mesmo gênero desses outros, os filhos-de-santo dos terreiros. Havia, pois, lugar para homens e mais de um gênero disponível para estes. Vale lembrar que enquanto indivíduos do sexo masculino vistos como homens, sem qualquer ambigüidade, esse lugar masculino foi ocupado freqüentemente por pesquisadores. Com efeito, há duas posições possíveis para indivíduos de sexo masculino na família-de-santo: aquele que partilha de suas relações de filiação, seja na condição de pai ou na de filho, e aquele que é exterior a essas relações pelo fato de não virar no santo, ou seja, não praticar o rito de possessão. Os que não praticam a possessão podem pertencer à família-de-santo na condição de $o g a \tilde{a}$. O ogã não partilha das relações consangüíneas, tal como as concebe a família-de-santo. Ocupa um lugar equivalente ao de pater e desfruta de um lugar de respeito como padrinho das iaôs no interior da família.

Ogãs e filhos-de-santo estão, pois, em campos diametralmente opostos: estes últimos se feminilizam e, quando iniciados, passam a virar no santo; os primeiros são considerados homens plenos exatamente porque, em vez de terem

11 LANDES R., A cidade das mulheres. Rio, Civilização Brasileira, 1947. 
um vínculo com essa esfera sobrenatural que feminiliza os homens, o orum, de certo modo 'representam' o aiê nas muitas ações rituais que exigem a elaboração do contato entre essas duas esferas. Com efeito, os ogãs dos terreiros são geralmente pessoas investidas de um tipo de obrigação relacionado ao seu pertencimento a esferas exteriores ao terreiro, em várias de suas dimensões. Geralmente são pessoas muito consideradas nas casas-de-santo, e o tipo de vínculo que possuem nestas não implica uma relação de subordinação ao seu responsável - podem falar em pé de igualdade com seus pais ou mães-desanto. As demonstrações ritualizadas de deferência, altamente valorizadas, incluem os ogãs, pela sua importância ritual, o que permite gerar bem-estar a todos os filhos e filhas da casa. Trata-se, portanto, de cargo investido de dignidade e de poder ritual.

As atividades que cabem aos ogãs e a respeitabilidade que possuem não são sempre as mesmas. Contudo, há em todas um elemento em comum — são atividades de mediação. Os ogãs são encarregados de tocar os atabaques, que 'chamam' os orixás - atividade essencial para contatar a esfera sobrenatural e permitir que a possessão se efetive. Essa atividade ritual possui uma equivalência simb6́lica com os outros encargos dos ogãs, mais freqüentes nas casas consideradas ortodoxas: a mediação com a sociedade, principalmente com suas esferas públicas de poder e a atividade ritual de sacrifício. A primeira dimensão é a que vem sendo ocupada por intelectuais e pesquisadores acadêmicos chamados de 'ogãs de salão', já que seus poderes 'fora' não os habilitam a realizar os ritos necessários 'dentro', principalmente os ritos de sacrifício, fundamentais para propiciar a abertura de um canal de contato com os orixás. ${ }^{12}$ Os chamados ogãs de faca são os que fazem a matança de animais, sacrifício essencial para que possa ocorrer a possessão. ${ }^{13}$ Como parte deste mundo, são mediadores do terreiro na relação com o outro mundo, cumprindo este papel através do toque dos atabaques e do sacrifício de animais. Mas também são mediadores por garantirem a existência, junto à sociedade dos homens, de um espaço associado ao mundo sobrenatural.

A linguagem do parentesco no candomblé se mostra fundamental para efetivar as relações entre seus integrantes. É através dela que se pode perceber o valor diferencial atribuído a pessoas em função do lugar que ocupam, associado por sua vez com o que de fundamental existe para os religiosos - a

12 Agradeço a Maria Lina Leão Teixeira essa informação que precisa as categorias religiosas envolvidas.

13 Ver o tex to de András Zempleni, "Possession et sacrifice", in Le temps de la réflexion, Paris, Gallimard, 1984, sobre a relação entre possessão e sacrifício. 
relação com seus santos. Entre irmãos e irmãs de santo temos referências a uma maior ou menor proximidade que se efetiva a partir da iniciação realizada por um mesmo pai ou mãe. Enquanto irmãos, todos possuem em comum não somente o mesmo terreiro, o mesmo pai ou mãe, mas também o mesmo gênero, pois, diferentemente dos ogãs, detêm, além da mesma filiação, uma característica dela decorrente, gerada com o processo ritual em que os filhos se iniciam. Trata-se da perda de uma certa qualidade enquanto homens, que permanece somente naqueles que, nos terreiros, não realizam o contato com a esfera dos orixás por intermédio da possessão. Além de irmãos-de-santo, irmãos de gênero. Esta dupla qualidade os distingue dos outros, ogãs. Vale ressaltar: o ogã é construído como aquele que simultaneamente é estranho às relações de sangue e diferente em termos de estatuto de gênero. Na família-desanto, representa o pólo masculino e o pólo exterior às relações consangüíneas. ${ }^{14}$

Essa qualidade diferencial que separa ogãs e filhos-de-santo associada simultaneamente ao estatuto de gênero e ao estatuto de parentesco, como vimos, permite compreender a presença de gêneros que não se confundem com aqueles elaborados na sociedade inclusiva. Dissemos que a possessão tem um efeito 'desvirilizante', o que não é a mesma coisa que dizer que a possessão 'produz bichas'. Para estarem plenamente concernidos à esfera masculina, os homens devem se manter distantes dos ritos de possessão. O que se pode observar como conseqüência desse conjunto de significados atribuídos à possessão é que os filhos-de-santo possuem certas características de gênero difíceis de serem apreendidas. São homens e, no entanto, são mais femininos; volta e meia fica sob suspeita a plenitude de sua adesão ao gênero que lhes é atribuído.

Temos, então, uma definição de gênero que, ao contrário da relação que se engendra entre os personagens da bicha e do homem, se faz por intermédio de pequenas nuances, como pequenos afastamentos do gênero masculino na sua integralidade. Esses afastamentos permitem suposições variadas a respeito das preferências sexuais de uns e outros (quando se confirmam, as suposições sobre as transas são argumentos mais definitivos para se classificar alguém quanto ao gênero). As aproximações e afastamentos se relacionam com muitos aspectos da vida no santo - quanto maior a distância da possessão (quanto mais velho no santo, menos se entra em transe), maior a respeitabilidade e, em

14 Para uma descrição e uma análise cuidadosas, numa outra perspectiva, da organização dos terreiros como familia-de-santo, ver COSTA LIMA V., Familia de santos dos candomblés e nagô da Bahia, Salvador, 1977, mimeo. 
decorrência, maiores também as qualidades associadas ao pólo masculino. ${ }^{15}$ Não se resume a esse aspecto, contudo.

Como observamos, esses afastamentos sutis e nuançados do estatuto de gênero masculino não dão conta desses outros personagens, considerados, no candomblé, equivalentes às bichas. Há alguma dimensão religiosa que lhes permite intensificar algo que, no caso dos filhos-de-santo, se mantém no plano discreto das suspeitas? Dissemos que a possessão, implicitamente, 'feminiliza' os indivíduos do sexo masculino e, ao lado disso, produz outro efeito: transforma o candomblé numa linguagem de duplo sentido. Com efeito, observar filhos-de-santo num toque, exercendo a dança dos orixás, poder apreender também um outro sentido, não explícito, obscuramente sexual, desta dança. Trata-se de uma linguagem que possui um nível secreto, impossível de ser nomeado claramente sem que se proceda uma redução grosseira.

Para melhor compreender essas articulações, temos que analisar o papel de gênero do adé. O personagem que se institui sob este termo é, na verdade, o especialista maior em explorar, através da possessão, o seu duplo sentido sexual e, assim, o seu sentido enquanto feminilidade. Em termos de gênero, não teríamos nenhuma peculiaridade a considerar se, frente aos procedimentos religiosos e às benesses que estes propiciam, não houvesse, por parte dos homens, uma atitude que contraria certos valores 'tradicionais' associados ao candomblé. A partir das virtualidades que efetivamente são fruto de sua concepção de mundo, os integrantes do candomblé podem fazer uso de moralidades diversas, sem que se vejam deslocados de suas inserções religiosas. A possessão, como operador da distinção entre os gêneros, é, neste caso, uma forma de sublinhar a aquisição dessa dimensão feminina. Não se trata mais da perda um tanto obscura da masculinidade, mas da minuciosa exploração do duplo sentido que a possessão permite: a sua ativa apropriação enquanto linguagem sexual. Os adés, ao contrário dos filhos-de-santo comuns, 'adoram'

15 A idéia de um continuum entre os pólos masculino e feminino fornecendo pequenas diferenciações entre os gêneros foi trabalhada numa mesma direção por Maria Lina Teixeira, "Transas de um povo de santo: um estudo sobre identidades sexuais" (dissertação de mestrado, IPCS/UFRJ, 1986) e Rita Laura Segatto, "Inventando a natureza: família, sexo e gênero no xangô de Recife," in Anuário Antropológico 85. Rio de Janeiro, Tempo Brasileiro, 1986. Ambas buscaram associar a cada um dos pólos qualidades provenientes da identificação do indivíduo com os seus orixás - quanto mais santos homens, mais masculina, quanto mais santas mulheres, mais feminina. Este argumento, no meu modo de entender, não dá conta do papel atribuído à possessão, mas permite que se valorize essas aproximações e afastamentos dos estatutos de gênero, que socialmente se apresentam mais nítidos e claramente configurados. 
o transe e a todo momento fazem questão de praticá-lo. Por isso têm, nos candombless, uma atividade em parte sujeita a censuras: o falso transe, denominado dar ekê. Os adés adoram dar ekê. Especialistas em possessão, eles fazem dessa habilidade algo que arrepia os bastiões de moralidade no candomblé, como mestres que são em apresentar falsas possessões. Dar ekê significa uma exibição paroxística de competência nesse domínio obscuramente sexualizado e feminino - domínio dessa linguagem que os ogãs e os filhos-de-santo sabem tão bem decifrar, que inclui muita técnica corporal, ritmo e gestual, num uso do corpo que ultrapassa em muito o transe descuidado e 'selvagem' que por vezes toma certos filhos e filhas.

Vejamos melhor o sentido que essa atividade assume. Dissemos que há uma relação de homologia entre aiê, umbanda e gênero masculino, em oposição a orum, candomblé e gênero feminino. A passagem da umbanda para o candomblé possui muitas dimensões: é simultaneamente uma passagem que envolve uma mudança de gênero, no caso dos indivíduos do sexo masculino, uma mudança na própria pessoa, já que esta adquire uma dimensão antes ausente, e uma mudança de identidade religiosa.

Todos esses planos adquirem materialidade plena nos ritos de possessão: é identificado como pertencente ao povo-de-nação aquele que souber realizar com exatidão os movimentos necessários dos ritos, souber cantar em nagô e, principalmente, souber dançar de acordo com o balé eterno dos orixás. A exibição de competência é assim um indicador precioso para distinguir nos indivíduos a presença dessas três dimensões articuladas: nessa exibição de competência, há um aspecto de virtuosismo que é valorizado. Ser de candomblé significa trazer para dentro do terreiro, o mais precisamente possível, esse mundo outro, na diferença radical que ele apresenta frente às experiências humanas e terrenas.

Nesse sentido, quanto melhor um filho-de-santo dançar, mais ele estará contribuindo para apresentar o valor próprio do candomblé e a diferença que este, inscrito na sua pessoa, permite a todos usufruir. Da mesma forma, quanto melhor 'pé de dança' ele for, mais claramente irá dispor da diferença que o transe introduz como uma diferença também de sentido sexual. O que disso resulta é que, em função do interesse que é próprio desses personagens em praticar a possessão, o 'falso transe' não raro apresenta no virtuosismo de sua execução um efeito mais espetacular que o 'verdadeiro', e o adé, como seu intérprete, é o personagem que o realiza com mais 'arte'. ${ }^{16}$ Os umbandistas,

16 O trabalho de Maria Lina Teixeira desenvolve de forma minuciosa e sugestiva essa dimensão ao mesmo tempo sexual e artística dos adés (LEÃO TEIXEIRA M.L., "Transas de um povo 
reconhecidos como homens, estão distantes das evoluções e maneirismos desses virtuosos do candomble e, conseqüentemente, não sofrem acusações em relação à sua virilidade. Além disso, os adés, considerados bichas, são aqueles que mais bem apresentam o candomblé na relação que este cultiva com o domínio dos orixás e com a feminilidade. Os adés não têm a mesma respeitabilidade que os outros integrantes das casas-de-santo. Será que esse tipo de prática religiosa não corresponde a um uso da religião que está em desacordo com seus princípios, calcados numa visão de mundo e de valores marcada pela tradicionalidade? Como, nesse caso, é possível dissociar o sentido religioso do sentido sexual e, ainda mais, dotar o segundo de importância maior que o primeiro? Como é possível deslocar do domínio do rito, com seus significados estritos, um sentido proveniente deste para outras esferas da vida social? Personagens polêmicos, os adés. De um lado, indispensáveis para garantir o brilho das festas; dão a seus pais-de-santo a certeza de que durante todo o toque haverá quem sabe efetivamente dançar com a destreza exigida pelos orixás. Por outro, são potencialmente vistos como fonte de problemas: no horizonte de todos, a imagem de momentos disruptivos, de grandes e pequenos desastres, se associa também à rebeldia dos adés.

Além de todas essas razões, existe uma outra, fundamental. Com efeito, os adés, apesar de constituírem personagens advindos dos terreiros e de terem uma atuação constante no exercício ritual das casas que freqüentam, não possuem uma inserção sólida nestas: em muitos casos, os adés não pertencem a qualquer terreiro. Simplesmente circulam entre vários, nos dias de festa, sem qualquer compromisso com as preocupações dos pais-de-santo. Presença ambígua, sem grandes compromissos com as casas em que comparecem, conseguem, apesar de tudo, ou mesmo por tudo isso, ter na frivolidade que apresentam a garantia de ser bem recebidos. São, portanto, exteriores ao menos a uma das dimensões dos terreiros, aquela em que as relações de filiação se materializam e os compromissos se efetivam —os terreiros enquanto núcleos domésticos.

Temos aqui um elemento importante para compreender outra dimensão dessas elaborações quanto ao gênero, propiciadas pelo candomblé. Trata-se da oposição que encontramos - tanto nesse universo religioso quanto na sociedade inclusiva - entre o sexo voltado para a reprodução e concernido à esfera doméstica e o sexo direcionado ao prazer, exterior a esta esfera. Ou ainda, em outros termos, a sexualidade feminina direcionada para a reprodução se distin- 
gue da sexualidade masculina, sempre nômade e múltipla. A organização dos terreiros enquanto núcleos domésticos tem na 'reprodução', ou seja, no cultivo cuidadoso da relação com os orixás, que inclui permanentemente ofazer novos filhos-de-santo, a sua razão fundamental de existência. Para a existência do núcleo doméstico, portanto, o que deve prevalecer em termos das relações de gênero é a presença de mulheres concernidas à sua esfera doméstica. Os homens, voltados para a esfera pública, exterior, são elemento de apoio à reprodução desse núcleo. A visão idealizada da família-de-santo enfatiza esses termos e, por isso mesmo, busca excluir da representação dos terreiros os homens vistos como bichas (seriam exceções à regra, presenças singulares e, por isso, pouco significativas) porque estes trazem para o interior das casas-desanto uma face sexualizada, em desacordo com a moralidade que se quer vigente. ${ }^{17}$ Com efeito, a materialidade que esses valores morais possuem não pode ser confundida com as condições de existência dessas casas, dependentes que estariam da vigência plena de suas normas. O fato é que, para além da ética de certos pais e mães-de-santo, os religiosos solucionam essas relações de gênero com os valores que lhes são concernidos de uma forma diversa.

$\mathrm{O}$ que ressalta é que, frente às mulheres, que inegavelmente ocupam o espaço doméstico, os homens que pertencem aos terreiros guardam todos certa exterioridade em relação a este espaço. É como se o eixo da reprodução só tivesse vigência plena no caso das mulheres, que, englobadas por esta ordem, são definidas ora como filhas, ora como mães. A pertinência das mulheres às lides domésticas se traduz, no plano religioso, como uma pertinência à possessão. Só que esta, significativamente, é 'esvaziada' das virtualidades que possui enquanto linguagem de duplo sentido. Definidas pelo espaço doméstico, as mulheres vão ter na possessão um instrumento de trabalho, um fazer associado à reprodução, muitas vezes representado como obrigações e desprazeres. Nada mais longe, com efeito, da imagem das mulheres do que este universo fútil dos adés. A adesão masculina à vida religiosa difere, nos seus motivos, da adesão feminina. As mulheres costumam entrar para o santo em função de problemas e 'aflições' diversas, e a possessão é justamente designada como trabalho para o santo e obrigação. O núcleo doméstico, ocupado por mulheres, é concebido como espaço da obediência e do trabalho.

17 Ver toda a bibliografia 'clássica' sobre o candomblé, notadamente a obra de Roger Bastide, Estudos afro-brasileiros (São Paulo, Perspectiva, 1973) e O candomblé da Bahia (São Paulo, Cia. Editora Nacional, 1978); Edson Carneiro e Nunes Pereira, A casa das minas (Petrópolis, Vozes, 1979). 
Portanto, na relação com a sexualidade, os dois eixos - 'reprodução' e 'prazer' - se duplicam na oposição interior/exterior ao espaço doméstico. Nessa medida, redimensionam o sentido dos gêneros, que vimos examinando. Em alguma medida os indivíduos do sexo masculino guardam certa exterioridade ao espaço da reprodução, ainda que não tenham em relação a ele uma atitude voltada para a 'rebeldia', como é o caso dos adés. Essa exterioridade, em outras palavras, significa a presença de uma sexualidade que não se subordina inteiramente ao eixo da reprodução, ainda que possa aceitar seus limites no interior da casa-de-santo. A carreira de pai-de-santo se inicia quando o indivíduo do sexo masculino consegue formar um núcleo doméstico constituído basicamente por mulheres, que garante o terreiro como uma família, na qual predominam relações filiais. Mas este pai, eventualmente considerado bicha, não será confundido com um adé - ao contrário deste, ele se propõe a ser um guardião do núcleo doméstico, uma autoridade paterna que garante, dentro de casa, as relações de respeito que devem nortear as atitudes dos filhos e filhas-de-santo.

Uma imagem que deixa transparecer de forma expressiva a duplicidade que constitui os indivíduos do sexo masculino como pais ou filhos-de-santo é aquela que os associa como indivíduos que incorporam e têm como protetores certas entidades femininas. Estas entidades guardam com esses indivíduos uma estreita relação de analogia, que se articula claramente com esse aspecto que estamos sublinhando: o pertencimento ao núcleo doméstico e, portanto, ao eixo da reprodução, por um lado, e por outro a presença de uma dimensão feminina que é exterior a esse eixo, direcionada para a possessão 'fútil' e 'gratuita'. Ora, essas entidades femininas, da predileção de alguns, apresentam exatamente essa dupla face: são santas mulheres que possuem como característica dominante $o$ fato de serem vistas, de certo modo, como mulheres sexualmente fogosas, ou seja, masculinas, não inteiramente subordinadas à esfera que as define como mulheres: são pomba-giras, entidades da umbanda referidas como exus femininos e que possuem como atributo básico uma sexualidade desenfreada.

No caso dos adés, essa relação é clara. A santa considerada protetora dos adés, ou seja, aquela que por gosto eles escolhem (o que não se confunde com os santos que o destino lhes atribuiu), é Iansã. Esta divindade, associada ao fogo e à fogosidade sexual, é considerada a rainha dos eguns, espíritos dos mortos. Lembremos que os eguns, no candomble, representam o pólo masculino. O proprio termo adé significa ornamento utilizado por Iansã. Temos assim pais-de-santo apresentando essa dupla face, concernidos simultaneamente ao interior/exterior do espaço doméstico. Seus santos protetores guardam uma expressiva analogia com os termos que, em diferentes planos, são constitutivos 
de suas identidades. Mulheres em certa medida masculinas (porque possuem uma face sexual não redutível à reprodução) são, preferencialmente, protetoras de homens em certa medida femininos (por não estarem apenas concernidos à esfera humana e terrena de domínio masculino). ${ }^{18}$

Temos, pois, uma construção dos gêneros que distingue o feminino e as mulheres e, em decorrência, atribui feminilidade plena a indivíduos do sexo masculino. Serão estes, dissociados também da esfera da reprodução mas guardando o contato com a sobrenatureza, os melhores artífices do candomblé.

A presença desses personagens, com todas as dimensões que os constituem, dá bem a medida da relação entre candomblé e sexualidade. É possível concluir dizendo que temos assim uma linguagem religiosa que se mostra propícia para exprimir sentidos sexuais, que por sua vez estão vinculados a uma dimensão social transgressora, distante de uma ética religiosa cristã. O contato com as dimensões divinas não aproxima indivíduo e valores morais associados à castidade, por exemplo. Ao contrário, pode impulsioná-lo a explorar cada vez mais intensamente o sentido transgressor de uma sexualidade que se expressa através dos ritos religiosos. A relação com os valores morais dominantes e, além disso, o próprio caráter da família-de-santo fazem com que o candomblé apresente uma ambigüidade irredutível: impossível 'expulsar' o duplo sentido de sua linguagem religiosa, da mesma forma como é impossível circunscrever o feminino às mulheres e, em decorrência, impedir que a possessão 'fútil' tenha lugar com a ênfase que se atribui à sexualidade.

\section{RESUMO}

\section{Relações de Gênero, Possessão e Sexualidade}

Este trabalho busca analisar as relações de gênero, tal como são concebidas nos cultos afro-brasileiros, notadamente no candomble. Analisa estas concepções na articulação que possuem com os ritos de possessão e trata da diferença que estes apresentam entre as vertentes religiosas constitutivas do campo afro. Busca compreender como os papéis de gênero na família-de-santo

18 Ovídio de Abreu Filho, "Dona Beija: análise de um mito," in FRANCHETTO B., CAVALCANTI M.L. e HEILBORN M. L. (orgs.), Perpectivas antropologicas da mulher 3 (Rio de Janeiro, Zahar, 1983) foi quem desenvolveu esse argumento em relação às identidades masculina e feminina no seu trabalho sobre o mito de Dona Beija, que como prostituta apresenta essas mesmas características. 
se desdobram na relação que o candomblé mantém com a sexualidade e com o espaço que the é concedido na prática cotidiana dos terreiros.

\section{ABSTRACT}

\section{Gender Relations, Possession and Sexuality}

The article explores gender relations as conceptualized by Afro-Brazilian religious cults, especially candomble. It analyzes these conceptions in their articulations with rites of possession and looks at the differences between such rites as practiced by different types of Afro-Brazilian religions. The objective is to arrive at an understanding of how gender roles within the família-de-santo develop in candomble's relation to sexuality and to the space it is assigned within daily practice at terreiros.

\section{RESUME}

\section{Rapports de Genre, Possession et Sexualité}

Ce travail s'efforce d'analyser les rapports de genre tels qu'il sont conçus dans les cultes afro-brésiliens, notamment dans le Candomblé. Il analyse ces conceptions dans leur articulation avec les rites de possession et traite des différences que ces derniers présentent dans chacun des courants religieux qui constituent le domaine Afro. L'auteur tente de comprendre comment, dans chaque "famille-de-saint", les rôles liés au genre se répercutent sur les rapports que le Candomblé entretient avec la sexualité et avec l'espace qui lui est concédé dans la pratique quotidienne des terreiros. 
. 